\title{
PROTEÇÃO DE MINORIAS E INCLUSÃO SOCIAL: A RESSOCIALIZAÇÃO DOS APENADOS A PARTIR DO DIREITO À EDUCAÇÃO NO CONJUNTO PENAL DE ITABUNA/BA
}

\author{
PROTECTION OF MINORITIES AND SOCIAL INCLUSION: THE RESOCIALIZATION OF \\ PRISONERS THROUGH THE RIGHT OF EDUCATION AT THE ITABUNA/BA PENITENTIARY
}

\author{
Fábio da Silva Santos* \\ Adriana Oliveira Lima**
}

\begin{abstract}
Resumo:
A presente pesquisa é uma breve investigação sobre os principais desafios e perspectivas que emergem do processo de ressocialização por meio da educação formal dos detentos do Conjunto Penal de Itabuna-BA. Inicialmente apresenta-se um percurso teórico e histórico sobre o sistema prisional brasileiro e sua evolução D’Urso (1999), Greco (2016), Mirabete (2008), Zaffaroni e Pierangeli (2007), dentre outros. Em seguida, explana-se os contextos da educação prisional brasileira e os processos de ressocialização e suas implicações consubstanciando-se por meio do exemplo das experiências dos apenados discentes e seus docentes na referida Instituição Penal. Esta pesquisa é exploratória e de campo, realizada com os sujeitos que participam diretamente desse processo no qual a educação formal embasa os procedimentos para a efetividade da lei de execução penal e a remissão da pena. No tratamento da análise qualitativa sobre os dados coletados (interpretação dos questionários) foram averiguados alguns pontos que circundam a realidade da sala de aula no contexto da prisão, tais como, motivo de optar a voltar ao estudo, condições físicas e pedagógicas e demais aspectos da relação da aprendizagem; com relação à equipe docente que participou da pesquisa foram também inquiridos a respeito dessa dimensão. Sendo assim, percebeu-se a importância da garantia de acesso à educação formal por meio do trabalho responsável dos professores e o interesse dos discentes apenados e quão relevante é a observância dos aspectos estruturais e ideológicos que permeiam as dificuldades e desafios pelos quais passam os sujeitos envolvidos. Daí que urge a preocupação em efetivar práticas
\end{abstract}

\footnotetext{
Doutorando em Direito Público pela Universidade Federal da Bahia (UFBA). Pesquisador do Centro e Grupo de Pesquisa em Proteção Internacional de Minorias (CEPIM) - Faculdade de Direito - Universidade de São Paulo - USP. Mestrado e Doutorado pela Universidade Salvador (UNIFACS) e Bolsista CAPES. Bacharel em Direito pela Universidade Estadual de Santa Cruz (UESC), Especialista em Direito Público e em Docência do Ensino Superior. Membro do Grupo de Pesquisa em Análise Econômica do Direito (UFBA), Educação e Desenvolvimento e em Cidades, Urbanismo e Urbanidades. Pesquisador do Instituto Geográfico e Histórico da Bahia. Líder do Grupo de Pesquisa em Direitos Humanos, Violência e Minorias Invisíveis (UNIRUY). Professor (Cursos de Graduação e Pós-Graduação) de Direito, Metodologia Científica e Pesquisa Jurídica (Centro Universitário Ruy Barbosa - UNIRUY Wyden Educacional; Faculdade Nobre de Feira de Santana - FAN, Unidade de Ensino Superior de Feira de Santana - UNEF, Universidade Católica do Salvador - UCSAL).

E-mail: fabiosantosdireito@gmail.com.

** Advogada. OAB/Bahia. Bacharela em Direito pela Faculdade de Tecnologia e Ciências - FTC. Licenciatura Plena em Ciências Habilitação Biologia pela Universidade Estadual de Santa Cruz (UESC).

E-mail: dri.lima05@gmail.com.
} 
penais e ações do Estado e sociedade civil com fins a assegurar a promoção do direito à ressocialização e legitimar melhorias das condições de execução penal no Brasil com a finalidade de enfrentar a situação cada vez mais alarmante dos Conjuntos Penais brasileiros.

Palavras-chave: Direito à educação. Conjunto Penal de Itabuna. Ressocialização.

\begin{abstract}
:
The present research is a brief investigation about the main challenges and perspectives that emerge from the resocialization process through the formal education of the prisoners at the Itabuna-BA Penitentiary. Initially, a theoretical and historical description about the Brazilian prison system and its evolution is presented by D'Urso (1999), Greco (2016), Mirabete (2008), Zaffaroni and Pierangeli (2007), among others. Then, the context of Brazilian educational system in prisons, the processes of resocialization of prisoners and their implications are explained, based on the testimony of the experiences of prisoners students and their teachers in that penitentiary. This work is characterized by a field research, carried out with the subjects who have directly participated in this process in which formal education is the basis of the procedures for the effectiveness of the Penal Execution Law and the reduction of penalties. In the treatment of the qualitative analysis of the collected data (interpretation of the questionnaires), some points were found that surround the reality of the classroom in the prison context, such as the reason for choosing to return to the study, physical and pedagogical conditions and other aspects of the learning; regarding the teaching staff that participated in the research, they were also asked about this dimension. Thus, it was realized the importance of ensuring access to formal education through the responsible work of teachers and the interest of prisoners students and how relevant it is, as well as the observance of structural and ideological aspects, which permeates the experienced difficulties and challenges by the involved subjects. Hence, the concern to carry out criminal practices and actions by the State and civil society is urgent in order to ensure the promotion of the right to resocialization and to legitimize improvements in the conditions of penal execution in Brazil with the purpose of facing the increasingly alarming situation of the Brazilian Penitentiaries.
\end{abstract}

Keywords: Right to Education. Itabuna Penitentiary. Resocialization of Prisoners.

\title{
1. Introdução
}

As prisões na sociedade moderna têm simbolizado o local onde o indivíduo paga pelo crime que cometeu através da reclusão, do isolamento do mundo "livre", ou seja, de um mundo socialmente construído por meio de valores benignos, com a finalidade de uma reinserção plausível. Constatam-se inúmeros fracassos com o sistema carcerário em colapso. A cadeia, de modo geral, constitui-se como uma "escola do crime", já que o apenado fica exposto a uma realidade voltada para a manutenção da criminalidade, isto é, realidade em que ocorre desrespeito aos direitos fundamentais, indo de encontro à sua dignidade e vivência minimamente efetiva de atividades de disciplina e reeducação. 
No entanto, o que deveria acontecer é o nominalmente chamado de processo de inclusão e reinserção social, pois é uma construção prática dentro do cotidiano do apenado; o desenvolvimento de uma rotina prescritiva normativa que contribua para o desenvolvimento dos aspectos sociais de comportamentos valorizados e almejados pela sociedade com o fulcro de proteção à tais minorias.

A resposta para a efetivação da ressocialização encontra amparo em políticas públicas que garantam a dignidade do indivíduo em todas as suas formas. Entre elas, a educação, pois pode oportunizar aos alunos apenados sua reintegração à sociedade, utilizando o saber sistemático, cujas experiências, crenças e objetivos são produtos da educação, proporcionando caminhos para a ressocialização e realização de uma outra visão, além dos muros da cadeia, através de um diálogo possível da cela à sala de aula, protegendo, efetivamente, tais minorias.

Assim, torna-se imperioso um estudo sobre os indicadores da valorização dos direitos humanos no âmbito do sistema prisional, por meio da educação, pela garantia da proteção de minorias, no que diz respeito à observância de sua dignidade, enquanto pessoa humana.

\section{A ressocialização no contexto prisional e o direito à educação}

A garantia da proteção das minorias baseia-se no aspecto moral da pena evidenciado pelo lado humano, com sua finalidade educativa. Isso graças ao comprometimento para com a recuperação do condenado, mediante ação reintegradora do mesmo no meio social, fazendo-o experimentar um recomeço, diante da sociedade, preparando o apenado para ser um membro produtivo e reeducado na convivência com seus semelhantes (FALCONI, 1998).

A ressocialização consiste na humanização do sujeito enquanto encarcerado pelo sistema prisional, buscando focalizá-lo de modo humanitário, tornando a ser apto para pertencer regularmente à sociedade, defendendo assim o bem comum. Por meio do reconhecimento da necessidade da ressocialização da pessoa condenada, a pena de prisão passa a ter uma nova intenção, além da simples supressão e detenção, passa a ter um desígnio de direção social e elaboração para o seu regresso à sociedade.

A ressocialização de apenados deriva de uma série de direitos adquiridos por meio da devida ação do Estado por meio da assistência. Uma delas é o direito à educação, previsto na lei de execução penal. A educação em direitos humanos nos presídios têm como fundamental intenção tornar o sujeito qualificado para que ele/ela possa procurar um futuro melhor ao cumprir sua pena, uma vez que o acesso aos bens intelectuais e a formação escolar são pressupostos básicos para adentrar ao mercado de trabalho, visto que a maior parte dos apenados não têm ensino fundamental completo (BRASIL, 1984). 
Para estimular o interesse dos apenados e a chance de refazer o caminho para a inserção social após o cumprimento da pena, foi promulgada, a exemplo do que ocorre com o trabalho, a remição da pena por estudo. Desse modo, a educação prisional, além de impulsionar o detento a procurar novos rumos, quando conseguir liberdade, proporciona também a diminuição do tempo da pena. Desse modo, todos os participantes possuem o direito de remição da pena em um dia, a cada três dias de aulas realizadas, conforme prevê a Lei de Execução Penal.

Urge a necessidade de reflexão crítica, no sentido de que a educação nas prisões representa um instrumento de proteção, transformação e inclusão do cidadão, de forma intrínseca, submetendo o indivíduo ao mundo do conhecimento e preparo para a vida extramuros.

\section{O direito à educação nas prisões - considerações fundantes}

A educação é direito de todo cidadão e tem amparo legal na seara internacional e nacional. A função do Estado é garantir os direitos da população no que diz respeito à educação. Isso não é diferente, quando se trata de uma parte da população que vive à margem da sociedade; um grupo que, no decorrer da história, tem sido colocado de lado, excluído das chamadas políticas públicas sociais.

Atualmente, o Estado da Bahia está construindo um Plano Estadual de Educação no seu Sistema Prisional, coordenado pela Secretaria da Administração Penitenciária - SEAP e a Secretaria da Educação - SEC. O texto teve como base as Diretrizes do Conselho Nacional de Educação, do Conselho Nacional de Políticas Criminais e Penitenciárias e a Lei n. 12.433/2011.

De acordo com Beccaria (2005), a mais de 200 anos já se questionava a majoração das punições e a prática da tortura e sabiamente se preceituava que o meio mais seguro, mas, ao mesmo tempo, mais difícil de tornar os homens menos inclinados a praticar o mal, é aperfeiçoar a educação. Não importa onde o indivíduo esteja, se fora ou dentro da prisão, a educação é o caminho para a liberdade intelectual, transformação do indivíduo e inclusão social, protegendo essas minorias invisíveis pela valorização dos direitos humanos, com vistas à inclusão social.

\section{Objetivos e metodologia}

A pesquisa tem por objetivo geral: Investigar quais os principais desafios e perspectivas no processo de ressocialização dos detentos por meio da educação formal no Conjunto Penal de Itabuna (CPI) - BA. Segundo Santos (2016, p. 50), "a cidade localizase no Sul do Estado da Bahia, em uma região denominada Costa do Cacau [...] a 426 
quilômetros da capital da Bahia, Salvador, é a quinta cidade mais populosa do Estado", com aproximadamente 221.046 pessoas (IBGE, 2016).

A unidade foi construída para atender 430 vagas, mas posteriormente foram construídos três anexos, o que proporcionou um aumento de sua capacidade para 670 vagas. No entanto, atualmente, não fugindo à regra da realidade enfrentada pelo sistema carcerário brasileiro, abriga 1.309 detentos. Não obstante, a estrutura física para suporte da população carcerária ainda permanece de 430. A capacidade de vagas do CPI destinase ao recolhimento de presos de ambos os sexos, condenados ao cumprimento de pena em regime fechado e semiaberto, e de presos provisórios de Comarcas relacionadas.

\section{Resultados e discussão}

Os sujeitos pesquisados foram 50 discentes e 8 docentes, que, interpelados sobre suas concepções e práticas, permitiram construir uma gama de conhecimentos sobre a realidade vivenciada e propiciada pelo âmbito do Direito e suas implicações para as questões sociais, no mundo cuja reclusão é fator condicionante para sua existência e vida.

Nesse sentido, discutem-se duas realidades concebidas e experienciadas no ambiente prisional, que, apesar de distintas, fomentam um importante processo na execução penal no Brasil. De um lado, temos a remição da pena pelo condenado e sua formação educacional, e do outro, o professor(a), inserido em um contexto diferente do “comum" à sua realidade pedagógica, numa dinâmica diferenciada, por causa de um sistema que limita a própria atividade docente.

Os discentes são 46 do sexo masculino e 4 do sexo feminino. A maioria na faixa etária entre 21 a 30 anos (38\%) dos participantes. Esses dados condizem com a realidade prisional brasileira, uma vez que, conforme relatório do IFOPEN, "a maior parte dos estabelecimentos penais foram projetados para o público masculino. $74 \%$ das unidades prisionais destinam-se aos homens, 7\% ao público feminino" (BRASIL, 2017, p. 19).

Desse modo, observamos que o CPI é mais um microcosmo que reflete a dimensão prisional brasileira, no qual a violência, a exclusão, a criminalidade são produtos da ação masculina.

A faixa etária de $74 \%$ da população carcerária no Brasil é de jovens entre 18 e 34 anos. Isto demonstra a relação existente entre juventude e criminalidade no país e pode direcionar as possíveis diretrizes para as políticas de direitos ao enfrentamento dessa realidade. De acordo com Novaes (2013, p. 25),

[...] problemas mais gerais da sociedade em que vivem os jovens devem ser cotejados tanto com critérios relativos à renda quanto a outros, que considerem os demais aspectos que produzem exclusão simbólica, social, econômica e 
política (tais como relações de gênero, raça, etnia, presença de deficiências, local de moradia).

Nesse sentido, a questão penitenciária brasileira perpassa a questão social, na qual a juventude está atrelada. Qualquer política pública voltada para essa realidade tem que necessariamente posicionar-se em relação ao jovem, à sua condição de vítima e de sua inserção social, de acesso à educação de qualidade, ao lazer e ao trabalho. $\mathrm{O}$ encarceramento e a condenação dos jovens em sua maciça regularidade é consequência de um sistema que insiste em não privilegiar a participação da juventude nas formas de condução política do país.

$\mathrm{Na}$ coleta realizada, a maioria dos respondentes indicou que a reintegração à sociedade foi o principal motivo de estudar. Esse dado confirma os principais estudos realizados no campo da educação prisional, que sugerem que estar inserido na sociedade é sinônimo de ressocializar-se, ou seja, para o apenado, a escola é o meio pelo qual ele volta a participar do convívio social.

O resultado obtido demonstra que a educação ao detento, em forma de instrução escolar, é importante na reeducação dos privados de liberdade, lhe oportunizando o seu retorno ao convívio familiar e social.

Apenas $6 \%$ responderam que a remição seria o principal motivo que o levou para a escola. Nesse sentido, vale ressaltar que a escola configura um ponto de partida para a ressocialização, uma vez que a remição não configura, para os apenados, fator principal para que frequente a escola. Outro dado importante é a busca pelo conhecimento, que configurou $20 \%$ das respostas. Tais resultados fortalecem o pensamento de Silva (2011 apud Fajardo, 2011), pois afirma que a educação não pode ser utilizada como moeda de troca dentro das prisões, mas sim como instrumento na busca pelo conhecimento e autonomia do sujeito, a fim de obter condições para competir no seu retorno à sociedade. Cerca de $90 \%$ dos alunos respondeu que no CPI é garantido o direito à educação básica para todos.

A Lei de Execução Penal (LEP) versa sobre a garantia para todos, porém a realidade é sombria, afinal, no CPI, não há salas de aula suficientes para atender à demanda. É preciso mais investimentos por parte da gestão prisional e mesmo do governo, para ampliar a capacidade física de atendimento à maioria dos detentos. Além de promover a valorização do educando apenado, possibilitando melhor tratamento ao mesmo, é preciso quebrar o preconceito e o estigma para que o apenado busque sua ressocialização por meio da frequência e acesso à educação formal.

É importante salientar que a matrícula para frequentar as aulas não é obrigatória e muitos optam por não estudar; mesmo aqueles que estão no regime semiaberto, que exercem outras atividades durante o dia, não gozam do privilégio de estudar, pois a escola funciona no diurno. 
Até $72 \%$ respondeu que é garantido o acesso ao ensino superior, contudo, de modo geral, os estudantes apenados não possuem uma consciência crítica com relação ao que seja educação de nível superior e o acesso a ela, até porque as condições de ensino para galgar uma adequada pontuação no Exame do Ensino Médio (ENEM) e chegar à Universidade/Faculdade são pouco significativas. Mesmo o tempo de execução/produção hora aula em condições prisionais não são as mesmas da maioria das salas de aula.

$\mathrm{O}$ questionamento sobre a qualificação dos professores e fiel cumprimento das atividades pedagógicas promovidas pela escola deixou claro a importância do papel do professor no processo de ressocialização, já que a maioria respondeu estar satisfeita com o trabalho desenvolvido.

Vale ressaltar o que disse Freire (1981), quando afirma que somente os seres que podem refletir sobre sua própria limitação são capazes de libertar-se desta. A educação transforma o cidadão a partir do seu interesse e, para não se perder no meio do caminho, é preciso um trabalho árduo do professor, afinal, o ambiente prisional difere do que ele está acostumado, necessitando maior domínio de classe, estratégias de ensino que conquistem seu aluno, compromisso, dedicação e coragem frente ao risco iminente de rebeliões.

Os procedimentos envolvendo revista no percurso que os detentos fazem da cela até chegarem à sala de aula, para $74 \%$ dos estudantes, não afetam a dinâmica para realização das atividades pedagógicas. Teixeira (2007, p. 18) afirma que "o desafio talvez seja definir uma equação em que educação e segurança não apareçam como antagônicas e que possam ser entendidas como coexistentes". Sendo assim, pensar práticas educativas em espaço prisional é administrar tensões existentes entre os profissionais da segurança pública e os interesses pedagógicos. Dentro da dinâmica social da aprendizagem, o apenado deve ser entendido como principal "alvo" desse processo, direito que pressupõe mudança de caráter cultural, isto é, repensando o aluno(a) apenado(a), destituindo-o de uma condição inferior de pessoa.

No universo dos entrevistados, $84 \%$ assinalou que o espaço físico da escola não é adequado. Dentre as opções apresentadas para sua melhoria, a maioria optou por laboratório de informática e inclusão digital, espaço com mais iluminação e ventilação, e sala de leitura/biblioteca dotada de acervo bibliográfico específico e atualizado e com profissional de apoio. A principal questão que se evidencia de modo mais aprofundado expõe a necessidade de práticas inclusivas de letramento digital, destacando a importância do uso dos recursos tecnológicos.

Quase metade dos discentes atribuiu, como maior desafio para aprendizagem, o tempo de permanência na sala de aula, seguida pelo turno de funcionamento vespertino, visto que, devido à rotina da cadeia, muitas vezes esse tempo não é disponibilizado na sua totalidade. 
Para $16 \%$ dos discentes, a principal assistência se dá quanto à merenda escolar, seguido do acesso e utilização de tecnologias da informação e comunicação, com $8 \%$. As condições da rede física e fardamento foram assinaladas por $6 \%$, ficando a biblioteca com percentual de $4 \%$.

Quando questionados, a coleta demonstrou que não há atendimento especializado para pessoas com necessidades especiais, através da promoção de adaptações arquitetônicas, aquisição de tecnologias assistivas e mobiliários adaptados, dados congruentes com os do relatório sobre a realidade nas prisões: "entre as pessoas com deficiência física, 64\% encontra-se em unidades que não foram adaptadas para suas condições específicas..." (BRASIL, 2017, p. 37).

Além da Educação nos Conjuntos Penais serem um direito do apenado, eles também têm garantidos por lei a participação em exames externos, como a certificação do Ensino Fundamental e Médio, por meio da Comissão Permanente de Avaliação CPA, Exame Nacional para Certificação de Competências de Jovens e Adultos Privados de Liberdade - ENCEJA/PPL e o Exame Nacional do Ensino Médio - ENEM/PPL. Na coleta, 42\% dos discentes apontaram que foram garantidas a participação no ENCEJA/ PPL e ENEM/PPL e 16\% nos exames estaduais, através da CPA.

Dos 50 discentes que responderam o questionário, 84\% apontam que o tempo oportunizado em sala de aula lhe possibilita refazer-se enquanto cidadão. Os apenados apostam na educação como uma válvula para o seu retorno à sociedade, buscando a reconstrução como cidadão. Nesse sentido, o Estado da Bahia recebeu destaque no último relatório sobre dados penitenciários, por possuir um dos "maiores percentuais de pessoas envolvidas em atividades educacionais, acima da média nacional" (BRASIL, 2017, p. 54). Esse é um dado importante para nortear as ações frente à educação carcerária, pois o caminho é árduo e estamos longe do atendimento ideal. Os dados coletados, 90\% entendem que o tempo disponibilizado em sala de aula pode contribuir para que possa se refazer enquanto cidadão, apoiando-o no seu processo de ressocialização.

A pesquisa realizada também contou com a participação dos professores daquela Unidade de Ensino, totalizando 100\% da amostra, ou seja, os 8 professores.

Metade dos docentes tem como motivação principal a realização profissional, 37\% estão lá por não terem conseguido vaga na Unidade sede, o que ocasionou sua excedência, ou seja, não ficaram programados em sala de aula, e 13\% admitiram que, além da realização profissional, estão lá por conta da gratificação que recebem da Secretaria de Segurança Pública do Estado da Bahia.

Para a metade dos professores, a oferta de educação para todos os discentes é garantida. Esse aspecto abre caminho para discussões acerta da oferta disponibilizada para o acesso à educação, uma vez que muitos dos detentos do CPI não estão na escola, talvez por não ter interesse ou por não haver tantas vagas para atender uma população 
carcerária que vive o mesmo drama de muitos presídios no Brasil, a superlotação. Nesse sentido, é pertinente uma reflexão sobre a efetividade da garantia de um direito que é primordial para o desenvolvimento intelectual do preso e do quanto a educação pode auxiliar esse indivíduo, enquanto cidadão para o seu retorno à sociedade.

Metade dos professores responderam que os apenados, após concluírem o Ensino Médio, não conseguem acesso ao ensino superior. Nesse sentido, vale lembrar que no CPI estão sob a tutela do Estado presos em regimes diferentes, provisórios, semiabertos e fechado, fato que em muitos casos inviabiliza a frequência do preso a uma faculdade presencial, realizada apenas por meio da autorização do juiz da vara de execução penal.

$\mathrm{O}$ direito à educação está relacionado com qualidade de ensino e para isso é imprescindível a regularidade das atividades pedagógicas e o cumprimento do que foi planejado, situação que é confirmada por cerca de $90 \%$ dos docentes. Os dados obtidos ainda demonstram que $60 \%$ dos docentes apontam o espaço como inadequado e inseguro para o trabalho. Como, para funcionamento do CPI e da educação prisional, o Estado e o Conjunto Penal contam com a cogestão por parte de uma empresa terceirizada, a Socializa, responsável pelo funcionamento e manutenção da Instituição Prisional, os docentes atribuem a inadequação e falta de segurança à falta de implantação do cogestionário de sala de leitura/biblioteca dotada de acervo bibliográfico específico e atualizado com apoio profissional, precariedade de iluminação e ventilação, falta de mobiliário, equipamentos e materiais pedagógicos, além de quantitativo reduzido de pessoal de apoio para o desenvolvimento das atividades pedagógicas. Metade dos docentes também atribuiu, como principal desafio à aprendizagem, o tempo de permanência na sala de aula.

Nesse contexto, $37,5 \%$ dos docentes assinalaram que o quantitativo de pessoal é suficiente para atender a demanda diária para o desenvolvimento das atividades planejadas e $88 \%$ desconhecem inclusive qualquer tipo de formação dos agentes penitenciários. De toda forma, para $75 \%$ dos docentes, é garantida a integridade física dos profissionais da educação, durante o desenvolvimento das atividades educacionais.

$\mathrm{O}$ resultado da pesquisa alerta para a necessidade de medidas efetivas a fim de garantir o trabalho dos docentes, pois o ambiente prisional, devido às suas especificidades, necessita de maior atenção, principalmente por conta do número de alunos e dos procedimentos rotineiros inerentes ao espaço prisional. Logo, fica evidente o quanto a realidade prisional brasileira caminha a passos lentos na busca de humanização dos espaços e condições dignas para que o educador consiga exercer o seu trabalho de forma a garantir aos apenados discentes o direito a uma educação de qualidade, com organização e segurança, para a realização e desenvolvimento das atividades pedagógicas.

Para Carvalho e Guimarães (2013),

Acreditamos que o maior desafio seja implantar ações educativas significativas em parceria com a área de 
segurança, a instituição penal institucionaliza e retira independência e autonomia das pessoas e a escola por outro lado liberta e leva a autonomia do ser humano.

$\mathrm{O}$ ambiente prisional traz consigo uma realidade diferente do ambiente social comum, pessoas estão sem liberdade, o local onde sobrevivem é cercado de segurança extrema e a superlotação, que é comum na maioria dos presídios brasileiros, são problemas que refletem diretamente na realidade educacional, pois o número de detentos que cumprem pena no CPI ultrapassa e muito a sua capacidade de lotação. A educação pública, no entanto, é um direito previsto na nossa Constituição, até mesmo para os privados de liberdade. Neste cenário, $87,5 \%$ dos docentes acredita na garantia da educação pública para os apenados, atendendo às especificidades inerentes às condições de vida e sobrevivência que permeiam a sua realidade, demonstrando que estão satisfeitos quanto ao atendimento às especificidades do local.

A capacitação para os agentes penitenciários, que atuam na educação, é de suma importância para garantia de direitos. Os docentes necessitam entender que, em uma prisão, as regras e seu cumprimento são elementos fundamentais para manutenção da ordem e segurança. Para metade deles, a Lei de Execução Penal, em seu art. 77 § $1^{\circ}$, que versa sobre os cursos específicos de formação e posteriormente de reciclagem periódica daqueles que estão em serviço (BRASIL, 2017) é cumprida.

A totalidade dos docentes assinalou que não é garantido atendimento aos discentes apenados com necessidades especiais, dado que mais uma vez reflete um desafio para efetividade do direito à educação, pois, além de encarcerado, o apenado com necessidades especiais vê seu direito negado, o que talvez inviabilize o seu ingresso na escola.

A educação promovida pelo Estado não é apenas formal, ela também acontece através da aplicação de exames, que tem por objetivo a certificação do indivíduo, do ensino fundamental ao superior, desta forma, $75 \%$ dos docentes assinalaram que é garantido a participação dos apenados no ENCEJA, ENEM e no CPA.

Entre os motivos que levam os apenados a frequentar a escola, os docentes destacaram igualmente a remição, o conhecimento e a reintegração. Contudo, considerado em separado, o conhecimento sozinho não foi considerado um fator motivador. Para $62 \%$ dos docentes, o tempo passado em sala possibilita o apenado na sua reconstrução.

A educação é um direito garantido por lei para todos, independentemente da sua condição na sociedade. Os muros feitos de concreto, as grades, os cães, as cercas de arame farpado impedem a locomoção daqueles que, por força dos seus atos, cumprem sua pena longe da sociedade comum. Todos esses mecanismos não têm o poder de escravizar e limitar a capacidade intelectual dos detentos e nem tão pouco negar direitos e garantias previstos na nossa carta magna, uma vez que a educação ainda é a maior e 
melhor arma que pode ser utilizada para reconstrução do indivíduo, esteja ele na condição de encarceramento ou não.

No que se refere à garantia desta oferta, ficou evidente que existe, na opinião tanto dos apenados quanto dos docentes, oferta para todos, uma vez que os detentos são informados sobre a matrícula e tem a autonomia para efetivá-la. No entanto, o destaque nessa questão é que o número de detentos no CPI passa dos 1.300. Ora, se todos decidissem estudar, o espaço destinado à escola não seria suficiente para atender à demanda. A LEP garante que todos tem o direito à educação, independente de qual regime o detento esteja inserido. Levando em conta o que foi observado, a realidade ainda difere do que diz a letra da lei, uma vez que os detentos, que cumprem pena no regime provisório, devido à sua condição de não terem sido julgados e que, após sentença, poderão retornar ou não para o CPI, tem seu direito cerceado em detrimento daqueles que já foram sentenciados. A oferta também não alcança aqueles que cumprem a pena em regime semiaberto, pois a escola não funciona no turno noturno. Nesse sentido, o desafio é atender um número maior de detentos independente de regime, pois tais restrições sugerem uma falha na questão estrutural que merece atenção especial, uma vez que, se a capacidade da instituição prisional estivesse sendo respeitada, a oferta educacional prevista na lei estaria bem perto de ser alcançada.

A cadeia é o lugar onde ninguém gostaria de estar, nem o preso e tão pouco aqueles que lá trabalham. A sociedade parece esquecer o mundo que existe por trás dos muros, esquecem que possivelmente aqueles que lá estão, após cumprida a pena imposta pela lei, retornarão para o mundo comum. Muitas pessoas têm pavor de pensar que um dia possam trabalhar no Conjunto Penal, por se sentirem ameaçados, por medo de rebeliões, de agressões e tantos outros motivos. Contudo, o direito à educação na prisão não se resume apenas em manter uma escola funcionando no seu interior, é preciso também garantir a funcionalidade dos direitos garantidos por lei. O apenado encontra-se sob a tutela do Estado e, sendo assim, para estudar necessita de condições para estabelecer o diálogo entre a prisão e a educação. Além da escola formal, os órgãos públicos também disponibilizam para os cidadãos a oportunidade de concluir o Ensino Fundamental e o Ensino Médio por meio de Exames, uma vez aprovado o indivíduo garante a sua certificação. Dentre esses exames, estão os exames estaduais de Educação de Jovens e Adultos, realizados pelas Comissões Permanentes de Avaliação - CPA, o exame Nacional para Certificação de Competências de Jovens e Adultos Privados de Liberdade - ENCEJA/PPL e o Exame Nacional do Ensino Médio - ENEM/PPL.

Num retrato de um momento de alegria e realização para a educação prisional, 3 detentos, que estudaram no Anexo ao Colégio Estadual de Itabuna no CPI, lograram aprovação para ingressarem na faculdade, especificamente nos cursos de Psicologia, Engenharia Civil e Direito. O acesso à faculdade ainda é de forma tímida, porém fica evidente que é possível alcançar esse patamar, mesmo estando encarcerado. 
Nos casos em tela, os discentes já estão em regime semiaberto. Nesse sentido, cabe transcrever a fala de um dos detentos naquele momento tão especial, disse ele: "quando fui preso, comecei a pensar que essa não era a vida que queria para mim. Tem um versículo da Bíblia, de autoria do apóstolo Paulo, que, escrevendo aos romanos, disse: 'detestai o mal, apegando-vos ao bem'. Adotei esse lema para minha vida, dali em diante. Essa é minha oportunidade de cumprir aquilo que decidi naquele dia - apegar-me ao bem e detestar o mal, para reconstruir minha vida a partir da educação".

\section{Considerações finais}

Ponderar sobre questões acerca do processo de ressocialização de apenados por meio da educação prisional, numa pesquisa, cujo tempo é escasso, não permite pontuar, de modo amplo, todas as teorias, conceitos e reflexões que possam fluir do entendimento desse processo. Partindo desse pressuposto, conclui-se aqui um pequeno recorte sobre as dimensões da realidade que circunscrevem a educação na instituição penitenciaria, sob o prisma do discente e docente, a partir do foco de alguns sujeitos pesquisados no Conjunto Penal de Itabuna (BA).

Observa-se que foi longo o processo de mudanças nas concepções sobre a ressocialização de presos apenados e consequentemente sobre o direito dos mesmos à educação, como forma de remição de pena e reinserção à sociedade, passando de uma perspectiva deturpada e pejorativa sobre o "condenado", para o entendimento no qual ele é um sujeito de direitos e pode ser protagonista de uma nova vida, ressocializada. Realidade que surge diante do entendimento de que a educação resulta na recuperação, na dimensão da garantia de direitos da pessoa que precisa de uma "segunda chance" para quitar o que deve e voltar a ser um cidadão de bem.

Seguindo os critérios que melhor delimitam a dimensão da educação prisional, para a execução desse direito aos apenados, verificou-se a efetividade da ressocialização e sua importância na melhoria das condições de vida deles. A Lei de Execução Penal, desde a sua criação, é um marco no ordenamento jurídico brasileiro, porque não dizer, um avanço perante o mundo. Preceitua medidas que visam a ressocialização do apenado, assegurando a ele o direito à educação. Afinal, esse não deve ser privilégio apenas de quem está em liberdade, pois esse indivíduo possivelmente retornará ao convívio social, portanto, nada mais justo que esteja preparado e reconstruído como cidadão para esse novo começo. No entanto, a LEP precisa ser respeitada e cumprida para garantir a efetividade dos direitos nela elencados, principalmente o direito à educação. Isso marca positivamente os processos de mudanças relativos à dimensão penitenciária e a garantia de direitos na sociedade brasileira. 
Assim, pode-se exemplificar essa realidade por meio das respostas aos questionários que os discentes e docentes efetuaram para a reflexão e embasamento desta pesquisa. Considerando, nesse sentido, os principais pontos que circundam a educação prisional e suas diretrizes, enfatizando e destacando as relações entre ensinoaprendizagem, condições estruturais (físicas, pedagógicas), dinâmicas de interações intraprisional, dentre outros fatores, que asseguram o desenvolvimento do processo de ressocialização através da educação, principalmente a partir do que pode ser concebido pelos sujeitos pesquisados.

Enfim, o processo de ressocialização dos apenados por meio do direito à educação é uma realidade ainda pouco discutida no Brasil, devido à realidade sombria enfrentada pelo sistema prisional, e a pouca preocupação que existe por parte da sociedade, pois prefere equivocadamente isolar a população carcerária, esquecendo que os encarcerados de hoje retornarão à sociedade. Contudo, cabe a reflexão sobre por que não voltar em melhores condições de enfrentar a vida fora dos muros da prisão. Afinal, a cela não é o fim, quando se tem a oportunidade de frequentar e vivenciar a sala de aula. Logo, essa questão ainda carece de reflexão, discussão e ação, a fim de garantir àqueles que estão encarcerados uma nova chance, uma nova vida a partir do conhecimento. Compreendese, portanto, a relevância efetiva de elucidar os fatores educacionais sobre a discussão do Direito partindo da realidade dos Conjuntos Penais e a importância da ressocialização de apenados através da garantia do acesso à sala de aula, mesmo que seu percurso comece da cela.

Foi observado que a principal contribuição do direito à educação, conferida aos apenados, se baseou no sentido da perspectiva da reintegração do indivíduo à sociedade, uma vez que, para $26 \%$ dos alunos, a escola é o caminho para o seu retorno ao convívio social.

Salvador, setembro de 2018.

\section{Referências}

BAHIA (Estado). Secretaria da Educação do Estado da Bahia e Secretaria de Administração Penitenciária e Ressocialização. Plano estadual de educação no sistema prisional da Bahia. Salvador, 31 ago. 2015. Disponível em: https:/www.gov.br/depen/pt-br/acesso-a-informacao/ acoes-e-programas/educacao-esporte-e-cultura/planoest-ed-emprises_itens_2015_emelaboraoba. pdf/view. Acesso em: 20 set. 2017.

BAHIA (Estado). Secretaria de Administração Penitenciária e Ressocialização. Conjunto penal de Itabuna. Disponível em: http://www.seap.ba.gov.br/pt-br/unidade/conjunto-penal-de-itabuna. Acesso em: 14 maio 2018. 
BATISTA, Nilo. Matrizes ibéricas do sistema penal brasileiro, I. Rio de Janeiro: Instituto Carioca de Criminologia, Freitas Bastos, 2013.

BECCARIA, Cesare. Dos meios de prevenir crimes. In: BECCARIA, Cesare. Dos delitos e das penas. 3. ed. São Paulo: Martin Claret, 2005.

BRASIL. Lei n. 12.433, de 29 de junho de 2011. Altera a Lei n. 7.210, de 11 de julho de 1984 (Lei de Execução Penal), para dispor sobre a remição de parte do tempo de execução da pena por estudo ou por trabalho. Portal da Câmara dos Deputados, Brasília, DF, 29 jun. 2011. Disponível em: http:// www2.camara.leg.br/legin/fed/lei/2011/lei-12433-29-junho-2011-610870-publicacaooriginal132991-pl.html. Acesso em: 21 nov. 2017.

BRASIL. Lei n. 7.210, de 11 de julho de 1984. Institui a Lei de Execução Penal. Portal da Câmara dos Deputados, Brasília, DF, 11 jul. 1984. Disponível em: https://www2.camara.leg.br/legin/fed/ lei/1980-1987/lei-7210-11-julho-1984-356938-normaatualizada-pl.doc Acesso em: 20 nov. 2017.

BRASIL. Ministério da Justiça e Segurança Pública. Departamento Penitenciário Nacional. SANTOS, Thandara (org.). Levantamento nacional de informações penitenciárias: INFOPEN atualização - junho de 2016. Brasília, DF, 2017. Disponível em: https://www.justica.gov.br/news/ ha-726-712-pessoas-presas-no-brasil/relatorio_2016_junho.pdf.

BRASIL. Ministério dos Direitos Humanos. Secretaria Especial de Direitos Humanos. Terceiro relatório nacional do Estado brasileiro ao mecanismo de revisão periódica universal do Conselho de Direitos Humanos das Nações Unidas - 2017. Brasília, DF, mar. 2017. Disponível em: http:// www.dedihc.pr.gov.br/arquivos/File/2017/RPUrelatorionacional2017portugues.pdf. Acesso em: 16 abr. 2018.

CALDEIRA, Felipe Machado. A evolução histórica, filosófica e teórica da pena. Revista da EMERJ, Rio de Janeiro, v. 12, n. 45, p. 255-272, 2009. Disponível: https://www.emerj.tjrj.jus.br/ revistaemerj_online/edicoes/revista45/Revista45_255.pdf. Acesso em: 10 fev. 2018.

CARVALHO, Odair França de; GUIMARÃES, Selva. A educação escolar prisional no Brasil sob ótica multicultural: identidade, diretrizes legais e currículos. Revista Horizontes, Itatiba, SP, v. 31, n. 2, p. 49-57, jul./dez. 2013. Disponível em: https://revistahorizontes.usf.edu.br/horizontes/article/ view/6/6. Acesso em: 25 nov. 2015.

CORSI, Éthore Conceição. Pena: origem, evolução, finalidade, aplicação no Brasil, sistemas prisionais e políticas públicas que melhorariam ou minimizariam a aplicação da pena. Âmbito Jurídico, Rio Grande, n. 149, jun. 2016. Disponível em: https:/ambitojuridico.com.br/cadernos/ direito-penal/pena-origem-evolucao-finalidade-aplicacao-no-brasil-sistemas-prisionais-e-politicaspublicas-que-melhorariam-ou-minimizariam-a-aplicacao-da-pena/. Acesso em: 13 de nov. 2017.

D’URSO, Luiz Flávio Borges. Direito criminal na atualidade. São Paulo: Atlas, 1999. p. 54. 
DULLIUS, Aladio Anastacio; HARTMANN, Jackson André Müller. Análise do sistema prisional brasileiro. Ambito Jurídico, Rio Grande, n. 95, dez. 2011. Disponível em: https://ambitojuridico. com.br/cadernos/direito-penal/analise-do-sistema-prisional-brasileiro/\#: :text=Os\%20 principais $\% 20$ problemas $\% 20$ no $\% 20$ sistema,presos $\% 20 \mathrm{j} \% \mathrm{C} 3 \% \mathrm{~A} 1 \% 20$ condenados $\% 2 \mathrm{C} \% 20$ aus\%C3\%AAncia\%20de. Acesso em: 20 out. 2017.

ESCOLA do presídio tem aula inaugural com palestra sobre educação e pertencimento. Agora, Itabuna, BA, ano 35, n. 4.387, p. 6, 1 a 6 mar. 2018. Disponível em: http://www.agora-online.com. br/noticias/educacao/1902-escola-do-presidio-tem-aula-inaugural-com-palestra-sobre-educacao-epertencimento. Acesso em: abr. de 2018.

FAJARDO, Vanessa. 'Educação não pode ser usada para esvaziar prisão', diz professor da USP. G1, São Paulo, 1 jul. 2011. Disponível em: http://g1.globo.com/educacao/noticia/2011/07/educacaonao-pode-ser-usada-para-esvaziar-prisao-diz-professor-da-usp.html. Acesso em: 25 out. 2017.

FALCONI, Romeu. Sistema presidial: reinserção social? São Paulo: Ícone, 1998.

FOUCAULT, Michel. Vigiar e punir: nascimento da prisão. 36. ed. Petrópolis: Vozes, 2009.

FREIRE, Paulo. Ação cultural para a liberdade e outros escritos. 5. ed. Rio de Janeiro: Paz e Terra, 1981.

GRECO, Rogério. Sistema prisional: colapso atual e soluções alternativas. 3. ed. Niterói: Impetus, 2016.

IBGE. Fundação Instituto Brasileiro de Geografia e Estatística. Enciclopédia dos Municípios Brasileiros. Brasília, 2016. Disponível em: http://www.biblioteca.ibge.gov.br. Acesso em: 19 maio 2018.

INTERNOS do conjunto penal de Itabuna começam a cursar faculdade. Portal Pimenta, [s. l.], 8 ago. 2017. Disponível em: http://www.pimenta.blog.br/2017/08/08/internos-do-conjunto-penal-deitabuna-comecam-a-cursar-faculdade/. Acesso em: 19 maio 2018.

MIRABETE, Julio. Fabbrini. Execução penal: comentários à Lei n. 7.210, de 11-07-84. São Paulo: Atlas, 2008.

NOGUEIRA, Paulo Lúcio. Comentários à lei de execução penal: Lei n. 7.210, de 11-7-1984. 3. ed. rev. e ampl. São Paulo: Saraiva, 1996.

NOVAES, Regina. Juventudes, diversidade e participação: desafios para governos e sociedade. Proposta: Revista Trimestral de Debate da Fase, Rio de Janeiro, ano 37, n. 126, p. 25-30, 2013. Disponível em: https://fase.org.br/wp-content/uploads/2014/05/proposta-127.pdf. Acesso em: fev. de 2018 .

OTTOBONI, Mário. Ninguém é irrecuperável: APAC, a revolução do sistema penitenciário. São Paulo: Cidade Nova, 1997. 
RIBEIRO, Jair Aparecido. Liberdade e cumprimento de pena de presos no sistema carcerário paranaense, 2009. Disponível em: http:/www.artigonal.com/direito-artigos/liberdade-ecumprimento-de-pena-de-presos-no-sistema-carcerario-paranaense-1518528.html. Acesso em: 20 out. 2017.

SANTOS, Fábio S. O Plano Diretor de Itabuna e seus desdobramentos na ampliação do ensino superior. 2016. Dissertação (Mestrado em Desenvolvimento Regional e Urbano) - Universidade Salvador - UNIFACS, Salvador, 2016.

SOARES, Luiz Eduardo et al. Violência e política no Rio de Janeiro. Rio de Janeiro: RelumeDumará, 2010.

TÁVORA, Nestor; ALENCAR, Rosmar Rodrigues. Curso de direito processual penal. 3. ed. Salvador: Editora JusPodivim, 2009.

TEIXEIRA, Carlos José Pinheiro. O papel da educação como programa de reinserção social para jovens e adultos privados de liberdade: perspectivas e avanços. Salto para o Futuro, Brasília, DF, n. 6, p. 14-21, maio 2007. Disponível em: https://s3-sa-east-1.amazonaws.com/tvescola/resources/ contents/document/publicationsSeries/1426102139217.pdf. Acesso em: 25 out. 2017.

VERDÉLIO, Andreia. Com 726 mil presos, Brasil tem terceira maior população carcerária do mundo. Agência Brasil, Brasília, DF, 8 dez. 2017. Disponível em: http://agenciabrasil.ebc.com. br/geral/noticia/2017-12/populacao-carceraria-do-brasil-sobe-de-622202-para-726712-pessoas. Acesso em: 15 fev. 2018.

WOLKMER, Antonio Carlos (org.). Fundamentos de história do direito. 5. ed. Belo Horizonte: Del Rey, 2010.

ZAFFARONI, Eugenio Rául; PIERANGELI, José Henrique. Manual de direito penal brasileiro: parte geral. 7. ed. rev. e atual. São Paulo: Revista dos Tribunais, 2007. v. 1. 